\title{
Cognitive abilities, androgen levels, and body mass index in 5-year-old children
}

\author{
Aitziber Azurmendi ${ }^{\mathrm{a}}$, Francisco Braza ${ }^{\mathrm{b}}$, Aizpea Sorozabal ${ }^{\mathrm{a}}$, Ainhoa García ${ }^{\mathrm{a}}$, Paloma Braza ${ }^{\mathrm{c}}$ \\ María R. Carreras ${ }^{\mathrm{c}}$, José M. Muñoz ${ }^{\mathrm{c}}$, Jaione Cardasa ${ }^{\mathrm{a}}$, José R. Sánchez-Martínª,T \\ ${ }^{a}$ Area of Psychobiology, Faculty of Psychology, University of the Basque Country, Av/Tolosa, 70, 20018 San Sebastian, Spain \\ ${ }^{\mathrm{b}}$ Doñana Biological Station, Spanish Council for Scientific Research (CSIC), Sevilla, Spain \\ 'Department of Psychology, Faculty of Sciences of Education, University of Cadiz, Puerto Real, Spain
}

\begin{abstract}
This study explores the potential relationship between a series of cognitive abilities and testosterone, dehydroepiandrosterone (DHEA), androstenedione, and body mass index (BMI) measurements in 5-year-old children. 60 boys and 69 girls were administered a test (K-BIT) which provided measurements of fluid intelligence (Matrices subtest), crystallized intelligence (Vocabulary subtest), and IQ composite (the combination of the two subtests); a sub-sample of 48 boys and 61 girls was also subjected to diverse tests related to theory of mind (affective labeling, appearance-reality distinction, display rules, and false belief). Testosterone, DHEA, and androstenedione levels were measured using an enzyme immunoassay technique in saliva samples. An analysis of variance failed to reveal any significant differences between boys and girls in any of the cognitive abilities assessed. The correlation analysis revealed a positive relationship between fluid intelligence and testosterone levels in boys, a negative relationship between crystallized intelligence and androstenedione levels in girls, and between affective labeling and androstenedione levels in boys. A multiple regression analysis indicated that androstenedione and BMI were the best predictors for some of the cognitive abilities assessed.
\end{abstract}

D 2005 Elsevier Inc. All rights reserved.

Keywords: Testosterone; Androstenedione; DHEA; BMI; Cognitive abilities; Crystallized intelligence; Fluid intelligence; Theory of mind

\section{Introduction}

There is currently a certain degree of consensus regarding the existence of a relationship between androgen levels and some cognitive abilities, although this relationship has hardly been studied at all in children. A number of studies, mainly carried out with adults, have analyzed the relationship between testosterone levels and some cognitive abilities for which gender differences have been established. Such abilities include, for example, certain spatial abilities, in which men tend to perform better than women. Some of these studies suggest a linear relationship

T Corresponding author. Fax: +34 943311055.

E-mail address: pbpsamaj@ss.ehu.es (J.R. Sánchez-Martín). between testosterone levels and visuospatial abilities (Christensen, 1993; Christensen and Knussman, 1987), while others suggest a non-linear relationship in which men with lower testosterone levels perform better in spatial tasks than men with higher testosterone levels, and women with higher testosterone levels perform better than women with lower testosterone levels (Gouchie and Kimura, 1991; Shute et al., 1983). Finally, other researchers failed to find any association between androgens and the cognitive function (McKeever et al., 1987). On the other hand, diverse studies have found an inverse association between BMI and different cognitive abilities (Halkjaer et al., 2003; Hirshman et al., 2004; Teasdale et al., 1992). Teasdale et al. (1992) found a negative relationship between intelligence and BMI, observing that intelligence scores reached their maximum value below the 
median for the body mass index and declined monotonically thereafter in young men. Similarly, in a sample of Chinese boys with a mean age of 9, Li (1995) found that boys with severe obesity had significantly lower IQ scores than controls.

A number of studies have also analyzed the relationship between androgens and cognitive abilities for which gender differences have not been identified, such as fluid intelligence for example. This type of intelligence has been related to adaptability and flexibility in response to the need to solve problems in unexpected situations and is commonly assessed by means of tasks involving matrices, series, and classifications, etc. Tan and Tan (1998) found that very low or very high levels of testosterone may have a negative effect on fluid intelligence in women, while in men, very low or medium levels of testosterone may have a positive effect, and very high testosterone levels a negative effect on this type of intelligence.

Another interesting line of research in the relationship between hormones and cognition is that connected to studies involving older citizens (the majority receiving exogenous hormone administration). A number of beneficial effects of the administration of replacement testosterone have been observed with regard to spatial cognition (Janowsky et al., 1994) and the visual working memory (Janowsky et al., 2000). For their part, in a study involving older women and men, Wolf and Kirschbaum (2002) found that women with more endogenous testosterone had a better verbal memory, while in men, a negative correlation was found between testosterone and verbal fluidity. Some studies have also analyzed the effects of the administration of DHEA on cognition, although the results are inconsistent (Wolf et al., 1997, 1998). Certain authors have suggested that the influence of DHEA on some cognitive abilities may be mediated by estrogens and testosterone (Hirshman et al., 2004).

The relationship between androgens and cognitive abilities in prepubescent children has not been widely researched, given that most studies have concentrated on young people and adults. When analyzing the relationship between perinatal testosterone levels and performance in spatial tasks at the age of 6, Jacklin et al. (1988) found that girls with higher levels of perinatal testosterone performed more poorly in the said tasks, while no relationship was observed in the case of boys. Finegan et al. (1992) found a negative relationship in girls between prenatal testosterone levels and performance in a spatial visualization test at the age of 4 , while no relationship was observed for boys. In another study, Grimshaw et al. (1995) found a positive correlation for girls between prenatal testosterone levels and mental rotation rate at the age of 7 . The results for boys were less clear, although they also suggested a positive relationship.

Traditionally, the early effects of hormones have been thought to be organizational in nature, since it is believed that they influence neural development and as a conse- quence of this, other physiological and behavioral processes also. Later effects, both activational and/or continuous, act on already existing neural systems. Androgen levels undergo a number of changes during human development (Collaer and Hines, 1995; CortésBlanco et al., 2000; Forest, 1989). For example, according to Forest (1989), at $10-12$ weeks of gestation, testosterone levels are higher in male fetuses than in female ones. From week 28 onwards, no gender differences have been found at all in relation to the levels of this hormone. During this phase, the temporary pattern for androstenedione is similar to that for testosterone. During the postnatal period, at the beginning of the second week, testosterone levels increase and reach their highest point some time around 20-60 days after birth, when the level is comparable to that found in adults. Afterwards, testosterone levels decrease until the seventh month, at which point all gender differences in this respect disappear again until puberty. During childhood, up to the age of 7 , sex steroids in plasma are as low as they will ever be during an individual's life. From this age onwards, until puberty, there is a gradual increase, mainly in DHEA and DHEA-S. In boys, testosterone levels increase 20-30 fold between the ages of 12 and 18 (this increase depends more on pubertal development than on chronological age). In girls, testosterone levels also increase during puberty, although at the end of this period boys have considerably higher levels than girls. In adulthood, testosterone levels are approximately 15 times greater in men than in women, and although there is a certain amount of controversy in relation to this area, a gradual decrease in levels has been observed from the age of 60-70 onwards. In menopausal women, testosterone levels are slightly lower than during the reproductive age.

One interesting aspect of cognition in children, which is particularly relevant from the perspective of social adaptation, is that related to theory of mind abilities. Between the ages of 3 and 5, children acquire a theory of mind, or in other words, the ability to understand other people's mental states, including beliefs, emotions, and desires, etc. (Astington, 1993; Wellman, 1990). Certain authors have found gender differences in relation to some of these abilities, such as in the case of an understanding of emotion, with girls generally performing better in this area than boys (Brown and Dunn, 1996; Dunn et al., 1991), although it is not clear at what precise moment these differences are established. Geary (1999) suggests the possible existence of endocrine correlates for these differences, although no experimental work has been carried out in this field. Nevertheless, other researchers have failed to find any gender differences whatsoever regarding the performance of diverse theory of mind tests (Roazzi and Santana, 1999; Simpson, 2003).

The study presented in this paper forms part of a wider project which aims to explore, from a biosocial perspective, the influence of diverse factors (family, cognitive, endo- 
crine, etc.) on young children's social adjustment to their social environment (peers). The study aims to explore the relationship between diverse cognitive abilities related to crystallized intelligence, fluid intelligence, IQ composite, and theory of mind and testosterone, DHEA, androstenedione, and BMI measurements in children.

Materials and methods

Subjects

The subjects were 129 preschool children (60 boys and 69 girls) from eight classrooms in three public schools in San Sebastian, Urnieta, and Puerto Real (Spain). The mean age of subjects in the sample was 5 years 5 months for boys and 5 years 4 months for girls, with the same range of 5 years 0 months to 5 years 11 months for both sexes. The socioeconomic status of subjects in the sample was medium and medium-high. The children's parents had been fully informed of the study and had given their consent.

\section{Procedures}

Cognitive abilities were measured throughout various sessions which were kept short in order to avoid tiring the subjects, thereby sustaining motivation during the task. In this way, cognitive tests were administrated to all subjects between 09:00 $\mathrm{h}$ and 10:00 $\mathrm{h}$ over a 4-week period. The tests were administered by qualified, trained researchers in a room adjacent to the classroom in each of the schools. In the case of theory of mind tests, finally, a sub-sample of 48 boys and 61 girls was used, because 10 subjects (from the total sample) were absent for various reasons on the days on which the theory of mind tests were administered and the correction of the tests carried out by the rest of the excluded subjects presented doubts regarding the process of the test, which was why they were eventually excluded.

Anthropometric measurements (weight and height), which were used to calculate the body mass index (BMI), were taken at the beginning of the first cognitive ability assessment session. Saliva samples, which were subsequently used for determining hormone levels, were taken on two occasions during the administration of the cognitive tests.

Although the tests used during this study were not invasive and were all carried out in the school itself, the project was pre-approved by the ethics committee at the university to which the authors belong.

\section{Measurement of cognitive ability}

Assessment of fluid intelligence and crystallized intelligence Fluid intelligence is the ability to resolve new problems. This type of intelligence is influenced by neurological development and is not affected by learning. It is reflected in tasks that require abstraction, the formation of concepts, perception, and eduction of relations, with the material used in the tasks being new for the subject (Rosén, 1995). This type of intelligence is thought to represent the biological substratum of intelligence (Cattell, 1971) and is involved in abilities such as induction, general reasoning, and cognition of figural relations. Crystallized intelligence, on the other hand, is the ability to use information which has been learned. It is reflected in tasks which require abstractions, formation of concepts, perception, and eduction of relation, but the material stimulants are, for the most part, conceptual-verbal in nature (Rosén, 1995) and are established through cultural pressure, education, and experience. This type of intelligence is involved in abilities such as verbal comprehension and cognition of semantic relations (Cattell, 1971). The Kaufman Brief Intelligence Test (K-BIT; Kaufman and Kaufman, 1994; Spanish adaptation by TEA ediciones, 2000) was used to measure these types of intelligence. The test provides three IQ measurements: Matrices (fluid intelligence), Vocabulary (crystallized intelligence), and IQ composite (combination of the two subtests).

\section{Theory of mind}

Four different types of tasks were used to assess subjects' understanding of other people's mental states (beliefs, emotions, intentions, etc.).

- Affective labeling. This task has been used in a number of studies on theory of mind (Brown and Dunn, 1996; Dunn et al., 1991) and assesses children's ability to recognize emotions. The task consists of labeling the emotions represented in a series of drawings, which depict expressions of happiness, sadness, anger, and fear.

- Appearance-reality distinction. This task, which was used by Banerjee (1997) and is based on a proposal made by Harris et al. (1986), uses a series of six stories to determine whether or not children understand the critical distinction between the appearance of an emotion and the reality of that same emotion. In other words, whether or not they understand that emotions is partly mental states and partly behavioral manifestations. Children heard six stories in which a child character was motivated to hide an emotion. Half of the stories involved positive emotions (happiness, joy, amusement), while the other half involved negative emotions (sadness, hurt). For example: "Amaia is playing a game with her friend Mikel. At the end of the game Amaia wins and Mikel loses. Amaia is really happy that she won. But, Amaia doesn't want Mikel to see how she feels because then Mikel won't play with her anymore. So, Amaia tries to hide how she feels. The subject must say what the protagonist actually felt and what feeling he/she expressed".

- Display rules. This task, which was also used by Banerjee (1997) and is based on a proposal by Saarni 
(1989), uses a series of six stories to determine whether or not subjects understand the coexistence of contradictory feelings towards a person in a specific situation. In this task, the child was explicitly told of the character's emotion and was asked if the character should show how she/he feels. For example: "Hello! I am Mikel. Let me tell you what happened to me today, because I need your help. I went over to grandma's house for lunch today, and she made a casserole. Boy, did it taste yucky. It tasted so bad, it made me want to scrunch up my face and just spit it out. Do you think I should act like it tastes good and just eat it, or should I tell grandma it tastes yucky and that I don't want to eat it? What do you think I should do?"

- False belief. The false belief task, created by Wimmer and Perner (1983), assesses whether or not children are capable of attributing to others beliefs that are different from their own. In this study, this ability was assessed using four stories that were similar to those used by Perner et al. (1994) and Astington and Jenkins (1995). The stories were acted out for the children using toys. For example, a girl doll put a crayon in her desk and went away. While she was gone, her brother took it out, drew a picture with it, and put it away in a cupboard. Then, the girl returned and wanted to draw with the crayon. The children were asked where she would look for it. Two control questions were also asked to check that they remembered the original location and knew the current location of the crayon.

\section{Determination of salivary hormone levels}

Testosterone, DHEA, and androstenedione concentrations in saliva reflect those in the free (non-protein bound) fraction of plasma (Granger et al., 1999a,b; Navarro et al., 1986; Otten et al., 1983; Riad-Fahmy et al., 1982; Vittek et al., 1985; Young et al., 1988) and subjects provide saliva more willingly than serum, meaning that samples can be collected without medical help. Salivary hormone measurement, therefore, provides a reliable, non-intrusive method of determining hormone titer.

Saliva samples were collected on two different occasions during the administration of the cognitive tests (both at the same time, 09:00 h, with an interval of 3 weeks) in order to obtain a base line for androgen levels in each subject. Saliva samples were taken by passive drool into a plastic cup. Samples were frozen and stored in the laboratory at $-80-\mathrm{C}$ until analysis.

On the day of the analysis, the samples were centrifuged at $3000 \mathrm{rpm}$ for $15 \mathrm{~min}$ to remove mucins. Both samples for each subject were assayed in duplicate. The average of each duplicate test was used in the analyses. All samples were assayed using an enzyme immunoassay kit (Salimetrics, State College, USA, for testosterone and DHEA; Dia.Metra, Foligno, Italy for androstenedione). For testosterone, the average intra-assay coefficient of variation (CV) was $6.7 \%(26.3 \mathrm{pg} / \mathrm{ml})$, and the average inter-assay $\mathrm{CV}$ was $9.6 \%(13.1 \mathrm{pg} / \mathrm{ml})$. For
DHEA, the average intra-assay CV was $6.8 \%(88.9 \mathrm{pg} / \mathrm{ml})$ and the average inter-assay CV was $8.4 \%(67.8 \mathrm{pg} / \mathrm{ml})$. For androstenedione, the intra- and inter-assay CVs were $5.6 \%$ and $3.4 \%$ respectively. The sensitivities of the kits were as follows: testosterone, $<1.5 \% \mathrm{pg} / \mathrm{ml}$; DHEA, $10 \mathrm{pg} /$ $\mathrm{ml}$; androstenedione, $5 \mathrm{pg} / \mathrm{ml}$.

The two values of each hormone were averaged, as they were correlated (testosterone: $\mathrm{r}=0.722, \mathrm{P}<0.01$; DHEA: $\mathrm{r}=0.309, \mathrm{P}<0.05$; androstenedione: $\mathrm{r}=0.500, \mathrm{P}<0.01$ ), with the result being a single score for each hormone.

\section{Statistical analysis}

Since they did not have a normal distribution, the theory of mind variables (affective labeling, etc.) were transformed using the Blom data transformation method (SPSS 11.5), which enabled us to use the same parametric tests for all analyses. The differences between the sexes in terms of their cognitive, hormone, and BMI measurements were analyzed by means of a one-way ANOVA. The relationships between the different scores for the different cognitive tests and the hormone and BMI levels were examined using Pearson's correlation coefficient.

Finally, a multiple regression analysis (stepwise) was carried out, using the hormonal and BMI measurements as independent variables and each of the cognitive abilities assessed as dependent variables. This analysis enabled us to determine the impact of each of the variables considered on the different cognitive abilities assessed.

\section{Results}

Gender differences in cognitive abilities, hormonal measurements, and BMI

No significant gender differences were found for any of the cognitive abilities studied. In the case of hormones, gender differences were only found for DHEA, with girls having higher DHEA levels than boys ( $\mathrm{F}=6.359$; $\mathrm{P}<0.05$ ). No gender differences were found for BMI.

Correlations between hormone measurements, BMI, and cognitive performance

As a first approximation, all correlations between defined cognitive variables and hormone and BMI measurements were based on combined data for both boys and girls. In this way, significant negative correlations were found between performance in the Vocabulary subtest and testosterone $(\mathrm{r}=$ $-0.178, \mathrm{P}<0.05)$, androstenedione $(\mathrm{r}=-0.207, \mathrm{P}<0.05)$, and BMI $(\mathrm{r}=-0.182, \mathrm{P}<0.05)$ levels and between IQ composite and androstenedione levels $(\mathrm{r}=-0.211, \mathrm{P}<$ 0.05). For the combined sexes, a significant positive correlation was also found between BMI and testosterone levels $(\mathrm{r}=0.199, \mathrm{P}<0.05)$. 
Table 1

Correlations between performance in cognitive tests and hormonal and BMI measurements in boys, using the Pearson correlation coefficient

\begin{tabular}{|c|c|c|c|c|}
\hline & Testosterone & DHEA & Androstenedione & BMI \\
\hline $\begin{array}{l}\text { Matrices (fluid } \\
\text { intelligence) }\end{array}$ & $r=0.298 \mathrm{~T}$ & $r=-0.156$ & $r=-0.187$ & $r=0.229$ \\
\hline $\begin{array}{l}\text { Vocabulary } \\
\text { (crystallized } \\
\text { intelligence) }\end{array}$ & $r=-0.069$ & $r=-0.004$ & $r=-0.143$ & $r=0.050$ \\
\hline IQ composite & $\mathrm{r}=0.167$ & $r=-0.121$ & $\mathrm{r}=-0.219$ & $\mathrm{r}=0.191$ \\
\hline $\begin{array}{l}\text { Affective } \\
\text { labeling }\end{array}$ & $\mathrm{r}=-0.159$ & $r=-0.281$ & $\mathrm{r}=-0.302 \mathrm{~T}$ & $r=-0.116$ \\
\hline $\begin{array}{l}\text { Appearance- } \\
\text { reality } \\
\text { distinction }\end{array}$ & $r=-0.035$ & $r=0.161$ & $r=0.032$ & $r=-0.091$ \\
\hline Display rules & $r=0.167$ & $r=0.112$ & $\mathrm{r}=0.035$ & $r=-0.019$ \\
\hline False belief & $r=0.058$ & $r=0.206$ & $r=0.116$ & $r=0.190$ \\
\hline
\end{tabular}

Tables 1 and 2 show the correlations between hormone measurements, BMI, and cognitive performance separately for boys and girls.

\section{Multiple regression analysis}

With the aim of analyzing the predictive power of each of the hormone measurements and BMI with regard to performance in cognitive tasks, a number of stepwise multiple regression analyses (Table 3 ) were carried out both for the combined sexes and for boys and girls separately. For the combined sexes, the best predictors of crystallized intelligence (Vocabulary subtest) were (negatively) BMI and androstenedione, which together accounted for $9 \%$ of the variance in this type of intelligence. Furthermore, androstenedione was also a predictor for IQ composite, accounting for just 5\% of the variance. For boys, the best predictor of affective labeling was (also negatively) androstenedione, which accounted for $13 \%$ of the variance in this cognitive ability. For girls, the best predictor of both crystallized intelligence and IQ composite was (negatively) BMI, which accounted for around $15 \%$ and $8 \%$ of the variance

Table 2

Correlations between performance in cognitive tests and hormonal and BMI measurements in girls, using the Pearson correlation coefficient

\begin{tabular}{|c|c|c|c|c|}
\hline & Testosterone & DHEA & Androstenedione & BMI \\
\hline $\begin{array}{l}\text { Matrices (fluid } \\
\text { intelligence) }\end{array}$ & $r=-0.087$ & $r=0.067$ & $r=-0.063$ & $r=-0.047$ \\
\hline $\begin{array}{l}\text { Vocabulary } \\
\text { (crystallized } \\
\text { intelligence) }\end{array}$ & $\mathrm{r}=-0.239$ & $r=-0.158$ & $\mathrm{r}=-0.241 \mathrm{~T}$ & $r=-0.305 T$ \\
\hline IQ composite & $r=-0.212$ & $r=-0.056$ & $r=-0.198$ & $r=-0.231$ \\
\hline $\begin{array}{l}\text { Affective } \\
\text { labeling }\end{array}$ & $r=0.037$ & $r=0.116$ & $r=0.060$ & $r=0.030$ \\
\hline $\begin{array}{l}\text { Appearance- } \\
\text { reality } \\
\text { distinction }\end{array}$ & $\mathrm{r}=-0.137$ & $r=-0.293 \mathrm{~T}$ & $r=-0.156$ & $r=-0.159$ \\
\hline Display rules & $r=-0.001$ & $r=0.073$ & $r=0.133$ & $r=-0.012$ \\
\hline False belief & $r=-0.053$ & $r=0.070$ & $r=-0.285 \mathrm{~T}$ & $r=0.004$ \\
\hline
\end{tabular}

Table 3

Multiple regression analysis (stepwise) of the androgen and BMI measurements for the different cognitive ability variables

\begin{tabular}{|c|c|c|c|c|}
\hline & & Beta & $\mathrm{t}$ & $\mathrm{P}$ \\
\hline \multicolumn{5}{|l|}{ Both genders } \\
\hline Crystallized intelligence & BMI & -.218 & -2.308 & $0.023 \mathrm{~T}$ \\
\hline $\begin{array}{l}R^{2}=0.093, \text { df }=104 \\
F=5.211, P=0.007\end{array}$ & Androstenedione & -.200 & -2.114 & $0.037 \mathrm{~T}$ \\
\hline $\begin{array}{l}\text { IQ composite } \\
\mathrm{R}^{2}=0.057, \mathrm{df}=104 \\
\mathrm{~F}=6.222, \mathrm{P}=0.014\end{array}$ & Androstenedione & -.239 & -2.494 & $0.014 \mathrm{~T}$ \\
\hline \multicolumn{5}{|l|}{ Boys } \\
\hline $\begin{array}{l}\text { Affective labeling } \\
\mathrm{R}^{2}=0.133, \mathrm{df}=37 \\
\mathrm{~F}=5.508, \mathrm{P}=0.025\end{array}$ & Androstenedione & -.364 & -2.347 & $0.025 \mathrm{~T}$ \\
\hline \multicolumn{5}{|l|}{ Girls } \\
\hline $\begin{array}{l}\text { Crystallized intelligence } \\
\mathrm{r}^{2}=0.153, \mathrm{df}=55 \\
\mathrm{~F}=9.776, \mathrm{P}=0.003\end{array}$ & BMI & -.392 & -3.127 & $0.003 \mathrm{TT}$ \\
\hline $\begin{array}{l}\text { IQ composite } \\
\mathrm{R}^{2}=0.087, \mathrm{df}=55 \\
\mathrm{~F}=5.164, \mathrm{P}=0.027\end{array}$ & BMI & -.295 & -.272 & $0.027 \mathrm{~T}$ \\
\hline $\begin{array}{l}\text { Appearance-reality } \\
\text { distinction } \\
\mathrm{r}^{2}=0.086, \mathrm{df}=47 \\
\mathrm{~F}=4.323, \mathrm{P}=0.043\end{array}$ & DHEA & -.293 & -2.079 & $0.043 \mathrm{~T}$ \\
\hline
\end{tabular}

(respectively). Furthermore, DHEA was also a predictor for appearance -reality distinction, accounting for just $8 \%$ of the variance.

\section{Discussion}

\section{Gender differences}

The study failed to find any gender differences in any of the cognitive abilities assessed. In the case of fluid intelligence (Matrices subtest), our results coincide with those found by Cattell (1987), Tan and Tan (1998) and Tan et al. (2003), who also failed to find any gender differences for this type of intelligence.

Our results also failed to show any significant differences in relation to crystallized intelligence (Vocabulary subtest), a result consistent with that obtained by Kaufman and Wang (1992), who found that male-female differences tended to be negligible in a test using the same instrument (K-BIT).

With regard to theory of mind, our results failed to show any significant gender differences in any of the tasks performed. These results coincide with those found by Roazzi and Santana (1999) and Simpson (2003) during diverse theory of mind tasks involving pre-school and school-age children. The results found by other authors in relation to affective labeling are controversial. In a recent study, Grimshaw et al. (2004) failed to find gender differences in the perception of facial emotions in adults. Diverse reviews (Brody, 1985; Groos and Ballif, 1991) have also 
been unable to confirm the existence of gender differences with regard to the processing of facial expressions in either pre-school or school-age children. However, a meta-analytic review carried out by McClure (2000) suggests a gender difference in favor of girls with regard to this skill. Furthermore, a number of authors (Brown and Dunn, 1996; Dunn et al., 1991) have found that girls show a better understanding of emotions than boys. Our results do not coincide with those found in these last studies. In a study involving children aged between 3 and 5, Banerjee (1997) observed gender differences with regard to specific aspects of their performance in appearance-reality distinction task and display rules task, a finding that was not reflected in our own results. It is probable that, from the age of 5 upwards, any gender differences that may exist with regard to certain theory of mind abilities tend to disappear.

As regards hormone levels, we failed to find any gender differences between testosterone and androstenedione. The lowest level of androgens occurs during the pre-school period (Forest, 1989), since the majority of circulating androgens in pre-pubescent children are produced by the adrenal glands and their levels are relatively stable (Ostatníková et al., 2000). Other studies have also failed to find gender differences in relation to testosterone and androstenedione levels in children (Cortés-Blanco et al., 2000; Strong and Dabbs, 2000). Nevertheless, gender differences were found with regard to DHEA levels, with those levels being significantly higher in girls than in boys. This finding coincides with that recorded by Granger et al. (1999b), who found higher DHEA levels in 8-year-old girls than in boys of the same age.

Relationship between cognitive abilities, hormone levels, and BMI

Few studies have considered the relationship between hormones and cognition in children, and those that have, have mainly analyzed the organizational influence of hormones on the performance of diverse cognitive tasks. This study, however, aimed to analyze the possible relationship between circulating androgen levels and a number of different cognitive abilities. Furthermore, the majority of studies involving both children and adults have mainly focused on those cognitive abilities for which there is a certain consensus regarding the existence of gender differences. In our case, we have approached the hormonecognition relationship from the perspective of abilities for which these differences have not been so clearly established or for which they have been simply dismissed, something which does not necessarily mean that no relationship exists between these abilities and hormone levels.

Almost all the relationships observed during our study between hormone measurements and cognitive performance are negative, that is, the higher the androgen level, the poorer the cognitive performance (except in the case of fluid intelligence).
The only positive relationship found between androgens and cognitive ability in our study was that observed between testosterone levels and fluid intelligence in boys. Although some studies involving children have failed to find any relationship between prenatal androgen levels and spatial ability in boys, these works assess the organizational influence of hormones (Finegan et al., 1992; Jacklin et al., 1988). Based on diverse pieces of evidence, it has been suggested that androgens may also have an activational influence on cognitive abilities, with fluctuations associated with changes in circulating testosterone levels being noted in the performance of spatial tasks (Kimura and Hampson, 1994; Van Goozen et al., 1995). A number of research projects have shown a negative association in men both between high levels of testosterone and spatial ability (Gouchie and Kimura, 1991; Moffat and Hampson, 1996; Shute et al., 1983) and between high levels of testosterone and fluid intelligence (Kutlu et al., 2001; Tan and Tan, 1998). Nevertheless, Krahnstöver and Susman (2001) found a positive linear relationship between testosterone and spatial ability in boys aged between 10 and 14 . Furthermore, Aleman et al. (2001) found a positive relationship in older men between high testosterone levels and fluid intelligence. Along the same lines, a number of studies have found that exogenous testosterone has a beneficial effect in older men (Cherrier et al., 2001; Janowsky et al., 1994). With regard to this type of intelligence, we can hypothesize that high testosterone levels after adolescence are associated negatively with performance of spatial tasks in men and, in general, with fluid intelligence, with medium and moderate scores in this measurement showing a positive relationship with this type of ability. If we bear in mind that testosterone levels tend to drop in older men, it is probable that exogenous testosterone contributes to the attainment of optimum levels for the performance of this type of activity. Returning to the results of this study, if we take into consideration that the androgen levels in the children comprising the sample group are among the lowest they will be during their entire lifetime and that even the highest levels are nowhere near those found in adults, we see that it is perhaps these high levels that are the optimum ones for the performance of these types of tasks during childhood.

If we look at crystallized intelligence, our results show a negative relationship between this type of intelligence and both testosterone levels (when both genders are taken into account together) and androstenedione levels (in the case of both the combined genders and girls alone). In fact, this last hormone, along with BMI, is a predictor for crystallized intelligence. Although Aleman et al. (2001) failed to find any relationship between crystallized intelligence and total serum testosterone levels in older men, Reuter et al. (2003) have suggested that high testosterone levels may interfere with educational acquisition during adolescence, thereby motivating subjects towards other types of activities and resulting in lower scores for crystallized thinking (since this type of thinking is the fruit of the knowledge and abilities 
obtained through learning and experience). We could therefore hypothesize that subjects with higher levels of androgens may, even during very early stages, present certain disadvantages linked to the performance of tasks related to the development of crystallized intelligence.

With regard to the relationship between androgen levels and the performance of diverse theory of mind tasks, we should point out that our results show a negative association between high androgen levels and affective labeling. In specific terms, we observed a negative relationship in boys between affective labeling and androstenedione, being this hormone a predictor for this cognitive ability (accounting for nearly $13 \%$ of the variance). The studies carried out by Bachevalier et al. (1989, 1990) found that high levels of circulating testosterone seemed to delay maturity in some regions of the temporal cortex in young male macaques, resulting in poorer performance of visual discrimination tasks. On the basis of these studies, McClure (2000) has suggested that a similar mechanism may apply also to humans in relation to the processing of the facial expression of emotions.

Another interesting aspect of our study is the discovery of a negative relationship between BMI and cognitive abilities. In this sense, we observed a negative relationship between crystallized intelligence and BMI for both the two genders combined and girls alone. Furthermore, in the case of girls, BMI was a predictor (albeit a weak one) of both crystallized intelligence and IQ composite. These results coincide with diverse findings that establish a negative relationship between BMI and cognitive abilities (Halkjaer et al., 2003; Hirshman et al., 2004; Teasdale et al., 1992). Since there is a hereditary component in both some cognitive abilities (Bouchard and McGue, 1981; Teasdale and Owen, 1984) and BMI (Price et al., 1987; Sorensen et al., 1989; Stunkard et al., 1986), it has been suggested that a number of potential genetic factors may be involved in this association (Teasdale et al., 1992). This hypothesis is supported by adoption studies (Teasdale et al., 1990) which found that the BMI of adopted adults was lower the higher the social class of their biological parents is. Furthermore, some authors (Halkjaer et al., 2003) have suggested that the biological channels leading to weight gain and eventually obesity may also imply disturbances of the brain function at higher levels than the hypothalamic regulation of energy balance.

In our study, we also found a positive correlation between testosterone levels and BMI. Although various studies have found a negative correlation between diverse steroid hormones (testosterone, DHEA, and androstenedione, among others) and BMI in young people and adults (Field et al., 1994; Ukkola et al., 2001; Vermeulen et al., 1996), Tremblay et al. (1998) failed to find any relationship between these two variables in subjects aged between 12 and 13, and Scerbo and Kolko (1994) also failed to observe any significant relationship between body mass and testosterone levels in subjects aged between 7 and 14. It is probable that the relationship between androgen levels and anthropometric measurements changes during an individual's lifecycle. One example of this is the period of pubertal maturity during which important changes take place in the body mass index, sexual steroids, and lipid profiles (Morrison et al., 2000). On the other hand, there is also evidence to suggest that obesity is related to alterations in the plasmatic concentrations of steroid hormones (Couillard et al., 2000). Furthermore, BMI, which often increases with age, seems to account for a significant amount of the variance observed in the majority of steroid hormones. This comes as no surprise, given that the age-related increase in BMI is mainly related to the accretion of body fat, and adipose tissue is an important place for the metabolism of steroids (Ukkola et al., 2001). It has been suggested that adipose tissue may act as a peripheral organ for converting androgens to estrogens. In fact, thanks to the effect of numerous enzymes, adrenal steroids (which are precursors of androgens and estrogens) can transform more powerfully into estrogens in obese patients, thereby helping reduce the amount of adrenal steroids in plasma (Couillard et al., 2000). It can't be ruled out the possibility that a similar process may occur in the subjects included in our sample.

The data obtained in our study enable us to conclude that there is a negative relationship between diverse cognitive abilities and androgen measurements and BMI, except in the case of fluid intelligence. Furthermore, BMI and androstenedione were found to be the best predictors for certain cognitive abilities in 5-year-old children, mainly crystallized intelligence, affective labeling, and IQ composite.

\section{Acknowledgments}

This study was supported by the Basque Country Government Grants (PI99/63; BFI02.118-AE) and the Dirección General de Investigación Científica y Técnica of Spain (Proyect BSO2002-00134). We would like to express our gratitude to the teaching staff, parents, and children of the Egape, Intxaurrondo Hegoa, and El Trocadero schools, to Mita Banerjee for providing us with certain theory of mind tests, and to Mercedes Lopez and Iñaki Verdier for helping us to collect the data.

\section{References}

Aleman, A., de Vries, W.R., Koppeschaar, H., Osman-Dualeh, M., Verhaar, H., Samson, M., Bol, E., de Haan, E., 2001. Relationship between circulating levels of sex hormones and insulin-like growth factor-1 and fluid intelligence in older men. Exp. Aging Res. 27, 283-291.

Astington, J., 1993. The Child's Discovery of the Mind. Harvard University Press, Cambridge, MA.

Astington, J., Jenkins, J., 1995. Theory of mind development and social understanding. Cogn. Emot. 9 (2/3), 151-165.

Bachevalier, J., Hagger, C., Bercu, B., 1989. Gender differences in visual habit formation in 3-moth-old rhesus monkeys. Dev. Psychol. 22, 585-599. 
Bachevalier, J., Brickson, M., Hagger, C., Mishkin, M., 1990. Age and sex differences in the effects of selective temporal lobe lesions on the formation of visual discrimination habits in rhesus monkeys. Behav. Neurosci. 104, 885-889.

Banerjee, M., 1997. Hidden emotions: preschoolers' knowledge of appearance-reality and emotion display rules. Soc. Cogn. 15 (2), $107-132$.

Bouchard, T.J., McGue, M., 1981. Familial studies of intelligence: a review. Science 212, 1055-1059.

Brody, L., 1985. Gender differences in emotional development: a review of theories and research. J. Pers. 53, 102-149.

Brown, J., Dunn, J., 1996. Continuities in emotion understanding from three to six years. Child Dev. 67, 789-802.

Cattell, R.B., 1971. Abilities: Their Structure, Growth and Action. Houghton-Mifflin, Boston.

Cattell, R.B., 1987. Intelligence: its structure, growth and action. In: Stelmach, G.H., Vroon, P.A. (Eds.), Advances in Psychology vol. 35. Elsevier Science Publishers, B.V., Amsterdam.

Cherrier, M.M., Asthana, S., Plymate, S., Baker, L., Matsumoto, A.M., Peskind, E., Raskind, M.A., Brodkin, K., Bremner, W., Petrova, A., LaTendresse, S., Craft, S., 2001. Testosterone supplementation improves spatial and verbal memory in healthy older men. Neurology 57, 80-88.

Christensen, K., 1993. Sex hormone-related variations of cognitive performance in Kung San hunter-gatherers of Namibia. Neuropsychobiology 27, 97-107.

Christensen, K., Knussman, R., 1987. Sex hormones and cognitive functioning in men. Neuropsychobiology 18, 27-36.

Collaer, M.L., Hines, M., 1995. Human behavioral sex differences: a role for gonadal hormones during early development. Psychol. Bull. 118 (1), 55- 107 .

Cortés-Blanco, A., Ferrández, A., Mayayo, E., Labarta, J.I., MartínezLázaro, R., 2000. Valores de referencia hormonales de función corticosuprarenal en niños sanos zaragozanos. An. Esp. Pediatr. 52 (2), 106-115.

Couillard, C., Gagnon, J., Bergeron, J., Leon, A.S., Rao, D.C., Skinner, J.S., Wilmore, J.H., Després, J., Bouchard, C., 2000. Contribution of body fatness and adipose tissue distribution to the age variation in plasma steroid hormone concentrations in men: the HERITAGE Family Study. J. Clin. Endocrinol. Metab. 85 (3), 1026-1031.

Dunn, Y., Brown, J., Slomkowski, C., Tesla, C., Youngblade, L., 1991. Young children's understanding of other people's feelings and beliefs: individual differences and their antecedents. Child Dev. 62, $1352-1366$.

Field, A.E., Colditz, G.A., Willett, W.C., Longcope, C., McKinlay, J.B., 1994. The relation of smoking, age, relative weight, and dietary intake to serum adrenal steroids, sex hormones, and sex hormone-binding globulin in middle-aged men. J. Clin. Endocrinol. Metab. 79 (5), 1310-1316.

Finegan, J.K., Niccols, G.A., Sitarenios, G., 1992. Relations between prenatal testosterone levels and cognitive abilities at 4 years. Dev. Psychol. 28, 1075-1089.

Forest, M.G., 1989. Physiological changes in circulating androgens. Pediatr. Adolesc. Endocrinol. 19, 104-129.

Geary, D.C., 1999. Male, Female. The Evolution of Human Sex Differences. American Psychological Association, Washington, DC.

Gouchie, C., Kimura, D., 1991. The relationship between testosterone levels and cognitive ability patterns. Psychoneuroendocrinology 16 (4), 323-334.

Granger, D., Schwartz, E., Booth, A., Arentz, M., 1999a. Salivary testosterone determination in studies of child health and development. Horm. Behav. 1 (35), 18-27.

Granger, D.A., Schwartz, E.B., Booth, A., Curran, M., Zakaria, D., 1999b. Assessing dehydroepiandrosterone in saliva: a simple radioimmunoassay for use in studies of children, adolescents and adults. Psychoneuroendocrinology 24, 567-579.

Grimshaw, G.M., Sitarenios, G., Finegan, J.K., 1995. Mental rotation at 7 years: relations with prenatal testosterone levels and spatial play experiences. Brain Cogn. 29, 85-100.

Grimshaw, G.M., Bulman-Fleming, M.B., Ngo, C., 2004. A signaldetection analysis of sex differences in the perception of emotional faces. Brain Cogn. 54, 248-250.

Groos, A.L., Ballif, B., 1991. Children's understanding of emotion from facial expressions and situations: a review. Dev. Rev. 11, 368-398.

Halkjaer, J., Holst, C., Sorensen, T.I., 2003. Intelligence test score and educational level in relation to BMI changes and obesity. Obes. Res. 11 (10), 1238-1245.

Harris, P.L., Donnelly, K., Guz, G.R., Pitt-Watson, R., 1986. Children’s understanding of the distinction between real and apparent emotion. Child Dev. 57, 895-909.

Hirshman, E., Merrit, P., Wang, C., Wierman, M., Budescu, D., Kohrt, W., Templin, J., Bhasin, S., 2004. Evidence than androgenic and estrogenic metabolites contribute to the effects of dehydroepiandrosterone on cognition in postmenopausal women. Horm. Behav. 45, 144-155.

Jacklin, C.N., Wilcox, K.T., Maccoby, E.E., 1988. Neonatal sex-steroid hormones and cognitive abilities at six years. Dev. Psychol. 21, 567-574.

Janowsky, J.S., Oviatt, S.K., Orwoll, E.S., 1994. Testosterone influences spatial cognition in older men. Behav. Neurosci. 108 (2), 325-332.

Janowsky, J.S., Chavez, B., Orwoll, E., 2000. Sex steroids modify working memory. J. Cogn. Neurosci. 12, 407-414.

Kaufman, A.S., Kaufman, N., 1994. Kaufman Brief Intelligence Test (K-Bit). American Guidance Service, Circle Pines.

Kaufman, A.S., Wang, J.J., 1992. Gender, race, and education differences on the K-BIT at ages 4 to 90 years. J. Psychoeduc. Assess. 10 (3), 219-229.

Kimura, D., Hampson, E., 1994. Cognitive pattern in men and women is influenced by fluctuations in sex hormones. Curr. Dir. Psychol. Sci. 3, 57-61.

Krahnstöver, K., Susman, E.J., 2001. Are hormone levels and cognitive ability related during early adolescence? Int. J. Behav. Dev. 25 (5), 416-428.

Kutlu, N., Ekerbicer, N., Ari, Z., Uyanik, B.S., Zere, T., Tan, Ü., 2001. Testosterone and nonverbal intelligence in right-handed men with successful and unsuccessful educational levels. Int. J. Neurosci. 111, $1-9$.

Li, X., 1995. A study of intelligence and personality in children with simple obesity. Int. J. Obes. Relat. Metab. Disord. 19 (5), 355-357.

McClure, E., 2000. A meta-analytic review of sex differences in facial expression processing and their development in infants, children and adolescents. Psychol. Bull. 126 (3), 424-453.

McKeever, W.F., Rich, D.A., Deyo, R.A., Conner, R.L., 1987. Androgens and spatial ability: failure to find a relationship between testosterone and ability measures. B. Psychon. Soc. 25, 438-440.

Moffat, S.D., Hampson, E., 1996. A curvilinear relationship between testosterone and spatial cognition in humans: possible influence of hand preference. Psychoneuroendocrinology 21 (3), 323-337.

Morrison, J.A., Sprecher, D.L., Biro, F.M., Apperson-Hansen, C., Lucky, A.W., DiPaola, L.M., 2000. Estradiol and testosterone effects on lipids in black and white boys aged 10 to 15 years. Metabolism 49 (9), 1124-1129.

Navarro, M.A., Juan, L., Bonnin, M.R., 1986. Salivary testosterone: relationship to total and free testosterone in serum. Clin. Chem. 32 (1), $231-232$.

Ostatníková, D., Laznibatová, J., Putz, Z., Mataseje, A., Dohnányiová, M., Pastor, K., 2000. Salivary testosterone levels in intellectually gifted and non-intellectually gifted preadolescents: an exploratory study. High Abil. Stud. 11 (1), 41-54.

Otten, B.J., Wellen, J.J., Rijken, J.C., Stoelinga, G.B., Benraad, T.J., 1983. Salivary and plasma androstenedione and 17-hydroxyprogesterone levels in congenital adrenal hyperplasia. J. Clin. Endocrinol. Metab. 57, 1150-1154.

Perner, J., Ruffiman, T., Leekman, S.R., 1994. Theory of mind is contagious: you catch it from your sibs. Child Dev. 65, 1228-1238. 
Price, R.A., Cadoret, R.J., Stunkard, A.J., Troughton, E., 1987. Genetic contributions to human fatness: an adoption study. Am. J. Psychiatry (144), 1003-1008.

Reuter, M., Netter, P., Henning, J., Mohiyeddini, C., Nyborg, H., 2003. Test of Nyborg's General Trait Covariance (GTC) model for hormonally guided development by means of structural equation modeling. Eur. J. Pers. 17, 221-235.

Riad-Fahmy, D., Read, G., Walker, R., Griffiths, K., 1982. Steroids in saliva for assessing endocrine function. Endocr. Rev. 3 (4), 367-395.

Roazzi, A., Santana, S., 1999. Theory of mind: the effect of age, sex, and the use of animate and inanimate "actors" in inferring mental states. Psicol. Reflex. Crit. 12 (2), 307-330.

Rosén, M., 1995. Gender differences in structure, means and variances of hierarchically ordered ability dimensions. Learn. Instr. 5, 37-62.

Saarni, C., 1989. Children's beliefs about emotion. In: Luszcz, M.A., Nettelbeck, T. (Eds.), Psychological Development: Perspectives Across the Life-Span. Elsevier Science Publishers, Holland.

Scerbo, A., Kolko, D.J., 1994. Salivary testosterone and cortisol in disruptive children: relationship to aggressive, hyperactive, and internalizing behaviors. J. Am. Acad. Child Adolesc. Psych. 33 (8), $1174-1184$

Shute, V.J., Pellegrino, J.W., Hubert, L., Reynolds, R.W., 1983. The relationship between androgen levels and human spatial abilities. B. Psychon. Soc. 21, 465-468.

Simpson, D.L., 2003. The role of culture and gender in children's development of display rules and theory of mind. Dissertation Abstracts International: Section B: The Sciences and Engineering 63(7-B), 3498.

Sorensen, T.I.A., Price, R.A., Stunkard, A.J., Schulsinger, F., 1989. Genetics of obesity in adult adoptees and their biological siblings. Br. Med. J. 298, 87-90.

Strong, R.K., Dabbs, J.M., 2000. Testosterone and behavior in normal young children. Pers. Individ. Differ. 28, 909-915.

Stunkard, A.J., Sorensen, T.I.A., Hanis, C., Teasdale, T.W., Chakraborty, W.J., Schull, W.J., Schulsinger, F., 1986. An adoption study of human obesity. N. Engl. J. Med. 314, 193-198.

Tan, Ü., Tan, M., 1998. Curvilinear correlation between total testosterone levels and fluid intelligence in men and women. Int. J. Neurosci. 95, 77-83.

Tan, Ü., Okuyan, M., Albayrak, T., Akgun, A., 2003. Sex differences in verbal and spatial ability reconsidered in relation to body size, lung volume, and sex hormones. Percept. Mot. Skills 96, 1347-1360.

Teasdale, T.W., Owen, D.R., 1984. Heredity and familial environment in intelligence and educational level: a sibling study. Nature 309, $620-622$.
Teasdale, T.W., Sorensen, T.I.A., Stunkard, A.J., 1990. Genetic and early environmental components in sociodemographic influences on adult body fatness. Br. Med. J. 300, 1615-1618.

Teasdale, T.W., Sorensen, T.I., Stunkard, A.J., 1992. Intelligence and educational level in relation to body mass index of adult males. Hum. Biol. 64 (1), 99-106.

Tremblay, R.E., Schaal, B., Buolerice, B., Arseneault, L., Soussignan, R.G., Paquete, D., Laurent, D., 1998. Testosterone, physical aggression, dominance and physical development in early adolescence. Int. J. Behav. Dev. 22 (4), 753-777.

Ukkola, O., Gagnon, J., Rankinen, R., Thompson, P.A., Hong, Y., Leon, A.S., Rao, D.C., Skinner, J.S., Wilmore, J.H., Bouchard, C., 2001. Age, body mass index, race and other determinants of steroid hormone variability: the HERITAGE Family Study. Eur. J. Endocrinol. 145, 1-9.

Van Goozen, S.H.M., Cohen-Kettenis, P.T., Gooren, L.J.G., Frijda, N.H., Van de Poll, N.N., 1995. Gender differences in behavior: activating effects of cross sex hormones. Psychoneuroendocrinology 20, 343-363.

Vermeulen, A., Kaufman, J.M., Giagulli, V.A., 1996. Influence of some biological indexes on sex hormone-binding globulin and androgen levels in aging or obese males. J. Clin. Endocrinol. Metab. 81 (5), 1821-1826.

Vittek, J., L’Hommedieu, D.G., Gordon, G.G., Rappaport, S.C., Southren, A.L., 1985. Direct radio inmunoassay (RIA) of salivary testosterone: correlation with free and total serum testosterone. Life Sci. 37 (8), $711-716$

Wellman, H., 1990. The Child's Theory of Mind. MIT Press, Cambridge, MA.

Wimmer, H., Perner, J., 1983. Beliefs about beliefs: representation and constraining function of wrong beliefs in young children's understanding of deception. Cognition 13, 125-138.

Wolf, O.T., Kirschbaum, C., 2002. Endogenous estradiol and testosterone levels are associated with cognitive performance in older women and men. Horm. Behav. 41, 259-266.

Wolf, O.T., Naumann, O., Hellhammer, D., Geiben, A.C., Strasburger, C.J., Dressendörfer, R.A., Pirke, K.M., Kirschbaum, C., 1997. Effects of a two-week physiological dehydroepiandrosterone substitution on cognitive performance and well-being in healthy elderly women and men. J. Clin. Endocrinol. Metab. 82 (7), 2363-2367.

Wolf, O.T., Naumann, O., Hellhammer, D., Kirschbaum, C., 1998. Effects of dehydroepiandrosterone replacement in elderly men on event-related potential, memory and well-being. J. Gerontol. 53, M385-M390.

Young, M.C., Walker, R.F., Riad-Fahmy, D., Hughes, I.A., 1988. Androstenedione rhythms in saliva in congenital adrenal hyperplasia. Arch. Dis. Child. 63, 624-628. 